04;06

\title{
Получение TiN-покрытий реактивным анодным испарением титана в разряде с самонакаливаемым полым катодом
}

\author{
(C) А.И. Меньшаков ${ }^{1,2}$, Д.Р. Емлин ${ }^{1}$ \\ ${ }^{1}$ Институт электрофизики УрО РАН, Екатеринбург, Россия \\ ${ }^{2}$ Уральский федеральный университет им. Б.Н. Ельцина, Екатеринбург, Россия \\ E-mail: menshakovandrey@mail.ru
}

Поступило в Редакцию 7 декабря 2020 г.

В окончательной редакции 7 декабря 2020г.

Принято к публикации 22 февраля 2021 г.

\begin{abstract}
Предложен способ получения TiN-покрытий путем анодного испарения титана в газовом сильноточном разряде $(30 \mathrm{~A})$ с самонакаливаемым полым катодом в среде $\mathrm{Ar}+\mathrm{N}_{2}$. Оптический спектральный анализ показывает, что в составе газоразрядной плазмы присутствует большое количество активированного титана, а доля ионов металла, поступающих из плазмы на подложку с учетом однозарядности ионов, достигает $70 \%$. При потоке азота $5 \mathrm{~cm}^{3} / \mathrm{min}$ получены ТiN-покрытия толщиной $2 \mu \mathrm{m}$ с твердостью до $24 \mathrm{GPa}$. Скорость осаждения на расстоянии $7 \mathrm{~cm}$ от источника паров составила $\sim 4 \mu \mathrm{m} / \mathrm{h}$.
\end{abstract}

Ключевые слова: нитрид титана, анодное испарение, самонакаливаемый полый катод, PVD.

DOI: 10.21883/PJTF.2021.10.50971.18646

Нитрид титана - одно из наиболее распространенных защитных покрытий. Он играет важную роль во многих промышленных приложениях благодаря своей твердости, высокой температуре плавления $\left(2950^{\circ} \mathrm{C}\right)$ и химической стабильности. Для промышленных приложений пленки TiN обычно получают путем магнетронного распыления Ті-мишени в азотсодержащей атмосфере, катодного распыления в дуговом сильноточном разряде и испарения сфокусированным электронным пучком. Плотные и твердые кристаллические покрытия формируются при достаточно высоком отношении потока ионов к нейтралам $j_{i} / j_{0}$ на подложку [1]. Поэтому при получении TiN-покрытий путем магнетронного распыления или испарения электронным пучком с высокой скоростью осаждения высокое соотношение $j_{i} / j_{0}$ часто достигается за счет дополнительной ионизации газа [2]. В вакуумно-дуговом разряде соотношение $j_{i} / j_{0}$ обычно составляет 7-10\% и обеспечивается высокая скорость осаждения до 20-50 $\mu \mathrm{m} / \mathrm{h}$ при токах от 100 А и выше [3]. Для многих приложений недостатком метода является наличие в плазменном потоке микрокапельной фракции, устранение которой дополнительными системами фильтрации приводит к уменьшению в несколько раз скорости осаждения и снижению энергии ионов.

Описанных выше недостатков может быть лишено получение покрытий на основе $\mathrm{TiN}$ посредством реактивного анодного испарения титана в разряде с самонакаливаемым полым катодом (СНПК). В таком разряде создается плотная плазма без использования отдельного источника ионизации парогазовой смеси и не применяются системы фильтрации, поскольку поток испаренного металла не содержит капельной фракции. Преимуществом предлагаемого подхода является то, что формирование и потока паров титана, и плотной плазмы происходит в одном разряде, при этом плотность ионного тока на поверхность образцов и скорость испарения металла могут независимо изменяться в широких диапазонах за счет использования секционного анода. Подобный подход применялся исключительно при получении покрытий $a-\mathrm{Al}_{2} \mathrm{O}_{3}$ путем испарения $\mathrm{Al}$ в кислородсодержащей плазме [4].

Возможность получения TiN-покрытий предлагаемым способом не является очевидной, поскольку ее реализации могут препятствовать недостаточная плотность мощности разряда, выделяющаяся на тигле, обеспечивающая необходимый поток паров $\mathrm{Ti}\left(T_{\text {melt }}=1671^{\circ} \mathrm{C}\right)$, и формирующийся тугоплавкий $\mathrm{TiN}$ на поверхности расплавленного металла в среде азота, ограничивающий скорость испарения Ті.

Целью настоящей работы является разработка метода осаждения металлических твердых нитридных покрытий путем управляемого анодного испарения титана в разряде с самонакаливаемым полым катодом, а также исследование особенностей плазмы, генерируемой в таком разряде.

Эксперименты проводились в газоразрядной системе на основе разряда с СНПК, схема которой представлена на рис. 1, а конструкция подобной системы детально описана в [5]. Особенностью разрядной системы является то, что разряд из СНПК 1 замыкался на двухсекционный анод 2 и 3. Одна секция (3), изготовленная из нержавеющей стали, имела водяное охлаждение, вторая секция анода (2) представляла собой тигель (графит МПГ-7) с Ті-навеской (ВТ1-0). Для лучшей теплоизоляции и обеспечения высокой плотности мощности на испаряемой поверхности тигель помещен в тепловые экраны из молибдена и керамической трубки. Ток разря- 


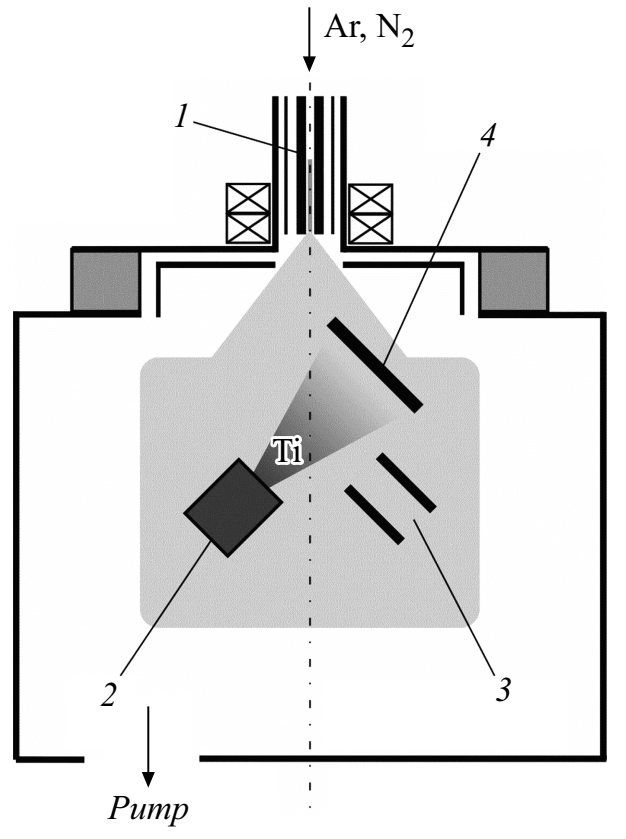

Рис. 1. Электродная схема экспериментальной установки. 1 - полый катод, 2 - анод-тигель, 3 - анод, 4 - столик с образцами.

да замыкался на открытую торцевую поверхность тигля диаметром $\sim 12 \mathrm{~mm}$.

На начальной стадии разряд зажигался в среде аргона $\left(Q_{\mathrm{Ar}}=40 \mathrm{~cm}^{3} / \mathrm{min}\right)$ между катодом 1 и охлаждаемым анодом 3. На этом этапе происходил разогрев полого катода в импульсно-периодическом тлеющем разряде и его переход в термоэмиссионный режим, характеризующийся низким напряжением и диффузной формой горения разряда. Ток разряда $I_{d}$ регулировался в диапазоне 10-50 А, при этом напряжение горения составляло 80-110 V. Затем подачей напряжения на тигель 2 часть тока разряда $I_{c r}$ переключалась на него. Температура тигля регулировалась изменением $I_{c r}$ в диапазоне 0-10 A.

Рост скорости испарения сопровождается усилением тока и снижением напряжения между тиглем и катодом с 350-400 V до величины, близкой к напряжению горения разряда между катодом и охлаждаемым анодом, что может объясняться возрастанием концентрации паров титана вблизи тигля малой площади и уменьшением прианодного падения потенциала. Измерение скорости испарения титана позволило установить, что плавление Ті достигается при токе $I_{c r}=1 \mathrm{~A}$ (мощность $\sim 200 \mathrm{~W})$. Изменением мощности, подводимой на поверхность тигля $\left(m_{\mathrm{Ti}} \sim 0.5 \mathrm{~g}\right)$, от 200 до $600 \mathrm{~W}$ $\left(I_{c r}=10 \mathrm{~A}\right)$ поток паров титана регулировался в диапазоне $\sim 10^{-5}-10^{-3} \mathrm{~g} / \mathrm{s} \cdot \mathrm{cm}^{2}$, скорость осаждения Тi на подложку соответственно менялась от 0.7 до $6 \mu \mathrm{m} / \mathrm{h}$.

Измерения плотности ионного тока насыщения $j_{i}$ на плоский односторонний зонд площадью $1 \mathrm{~cm}^{2}$ в области расположения образцов показали, что при включении тигля существенно (в 23 раза) повышалась плотность тока на обрабатываемые образцы (рис. 2). В отсутствие тока в цепи тигля увеличение разрядного тока до $I_{d}=50$ А приводило к росту плотности ионного тока до $10 \mathrm{~mA} / \mathrm{cm}^{2}$. При включении тигля с током в его цепи $I_{c r}=5 \mathrm{~A}$ эта же величина плотности ионного тока достигалась при половинном суммарном токе $I_{d}=25 \mathrm{~A}$. Если судить о доле ионов титана на поверхность образцов по приращению ионного тока при испарении металла, то при фиксированном токе на охлаждаемый анод в смеси $\mathrm{Ar}+\mathrm{N}_{2}$ рост тока на тигель $I_{c r}$ от 0 до $10 \mathrm{~A}$ позволяет повысить долю тока металлических ионов на образцы до $\sim 60-70 \%$. Плотность ионного тока при этом достигает $\sim 20 \mathrm{~mA} / \mathrm{cm}^{2}$.

Методом оптической эмиссионной спектроскопии с помощью спектрометра HR2000 (OceanOptics, paбoчий спектральный диапазон 200-1100 nm, разрешение $0.8 \mathrm{~nm})$ исследован состав плазмы в смеси аргона и азота с титаном в области осаждения покрытий. Во всех режимах горения разряда в спектрах наблюдаются линии плазмообразующих газов $\left(\mathrm{Ar}^{*}, \mathrm{Ar}^{+}, \mathrm{N}_{2}^{*}, \mathrm{~N}_{2}^{+}\right)$и линии возбужденных атомов ( Ti* $^{*}$ - 399.9, 453.3, 498.2, $504 \mathrm{~nm})$ и ионов титана $\left(\mathrm{Ti}^{+}-337.3,364.3,374.2 \mathrm{~nm}\right)$ (рис. 3). В отличие от работы [6], в которой показано, что средняя зарядность ионов, поступающих из катодной дуги низкого давления, составляет 2.1, линии двухзарядных ионов $\mathrm{Ti}^{2+}$ в плазме анодной дуги на фоне интенсивных линий $\mathrm{Ti}^{*}$ и $\mathrm{Ti}^{+}$выделить не удалось: можно предположить, что в анодной области плазмы преимущественно возникают однозарядные ионы из-за ионизации атомов титана в потоке быстрых электронов с энергией до нескольких десятков eV [7], поступающих

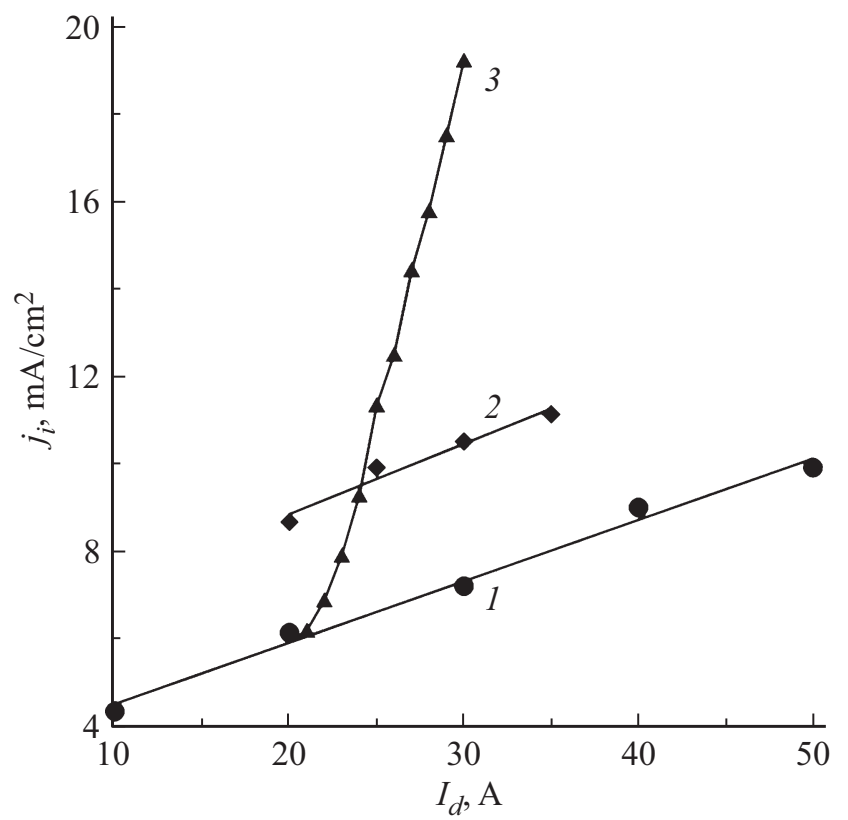

Рис. 2. Зависимости плотности ионного тока насыщения от полного тока разряда в среде аргона. 1- без включения тигля; $2-I_{c r}=5 \mathrm{~A}$, ток на анод $15-30 \mathrm{~A} ; 3-$ ток на анод $20 \mathrm{~A}$, ток в цепи тигля $0-10 \mathrm{~A}$. 


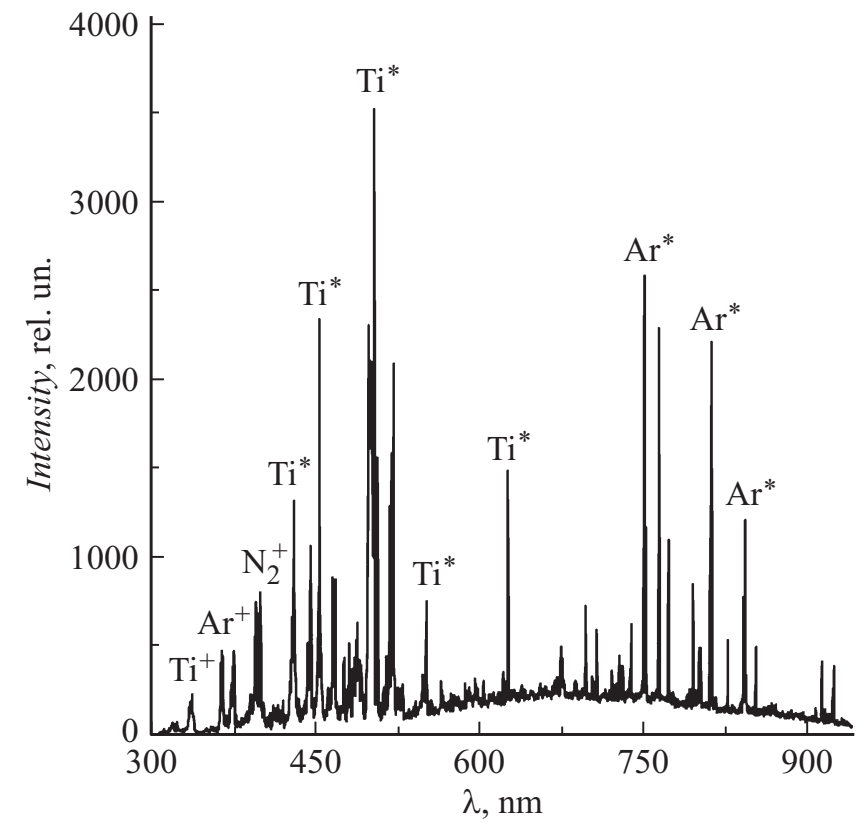

Рис. 3. Оптический спектр плазмы разряда. $I_{d}=20 \mathrm{~A}$, $Q_{\mathrm{N}_{2}}=10 \mathrm{~cm}^{3} / \mathrm{min}, I_{c r}=5 \mathrm{~A}$.

из СНПК на тигель. Интенсивность линий Ті в спектрах выше интенсивности линий Ar, что свидетельствует о высокой концентрации и степени активации паров металла.

Тестовые покрытия получены при токе разряда $I_{d}=25 \mathrm{~A}$ и токе в цепи тигля $I_{c r}=3 \mathrm{~A}$. Покрытия наносились на образцы из нержавеющей стали AISI430 и кварцевого стекла, расположенные вблизи оси катода на расстоянии $7 \mathrm{~cm}$ от тигля. Перед осаждением проводилась очистка поверхности образцов ионами $\mathrm{Ar}^{+} \mathrm{c}$ энергией $500 \mathrm{eV}$ при плотности тока $5 \mathrm{~mA} / \mathrm{cm}^{2}$ в течение $5 \mathrm{~min}$. Для обеспечения хорошей адгезии между покрытием и материалом основы перед осаждением наносился подслой Ті толщиной $\sim 200 \mathrm{~nm}$, после чего потенциал образцов снижался примерно до $-100 \mathrm{~V}$ относительно анода и в камеру подавался $\mathrm{N}_{2}$.

Особенностью нагрева титана в азотсодержащей газовой среде является его интенсивное азотирование при высоких температурах с формированием TiN на испаряемой поверхности, который в свою очередь имеет значительно более низкое давление насыщенных паров [8], т.е. появление пленки TiN на поверхности расплава металла будет фактически блокировать испарение титана. При этом скорость азотирования возрастает с ростом концентрации азота вблизи поверхности. Для предотвращения формирования твердого раствора азота в титане с последующим образованием нитридного слоя на испаряемой поверхности азот напускался в камеру после начала плавления Ті. Установлено, что для формирования стехиометрического покрытия TiN достаточно потока азота $\sim 5-6 \mathrm{~cm}^{3} / \mathrm{min}$; низкое содержание $\mathrm{N}_{2}$ в газовой среде $\left(P_{\mathrm{N}_{2}} \sim 5 \cdot 10^{-3} \mathrm{~Pa}\right)$ компенсируется высокой степенью его активации потоком быстрых электронов. Давление газовой смеси $\left(\mathrm{Ar}+\mathrm{N}_{2}\right)$ в процессе осаждения составляло $0.04 \mathrm{~Pa}$.

Толщина покрытий, измеренная методом шарового истирания на приборе Calotest, за цикл длительностью $30 \mathrm{~min}$ составила $\sim 2 \mu \mathrm{m}$, а их микротвердость, измеренная с помощью динамического микротвердомеpa Shimadzu DUH-211s на нагрузке $10 \mathrm{mN}$, составила $\sim 22-24 \mathrm{GPa}$. XRD-анализ, выполненный на дифрактометре XRD-7000 (Shimadzu) в медном $K_{\alpha 1}$-излучении с использованием графитового монохроматора на вторичном пучке, показал, что основной фазой в покрытии является кубическая фаза TiN c размером области когерентного рассеяния $\sim 6 \mathrm{~nm}$ и преимущественной ориентацией (200). Отношение количества ионов к числу атомов титана на поверхности образцов с учетом косинусоидального распределения потока паров металла составило $j_{i} / j_{0} \sim 2.9$.

Таким образом, впервые исследован способ осаждения $\mathrm{TiN}$-покрытий путем анодного испарения титана в дуговом разряде с самонакаливаемым полым катодом. Показано, что такой подход обеспечивает высокую скорость испарения титана (до $\sim 10^{-3} \mathrm{~g} / \mathrm{s} \cdot \mathrm{cm}^{2}$ ), высокую степень активации его паров (доля $\mathrm{Ti}^{+}$до $\sim 70 \%$ ) и интенсивное ионное сопровождение $\left(j_{i} \sim 20 \mathrm{~mA} / \mathrm{cm}^{2}\right)$, необходимые для формирования твердых $\mathrm{TiN}$-покрытий с высокой скоростью. Получены покрытия толщиной $2 \mu \mathrm{m}$ с твердостью $24 \mathrm{GPa}$ со скоростью $4 \mu \mathrm{m} / \mathrm{h}$.

\section{Финансирование работы}

Работа выполнена при поддержке Российского научного фонда (проект № 20-79-10059).

\section{Конфликт интересов}

Авторы заявляют, что у них нет конфликта интересов.

\section{Список литературы}

[1] A. Anders, Thin Solid Films, 518 (15), 4087 (2010). DOI: $10.1016 /$ j.tsf.2009.10.145

[2] J.-W. Lim, H.-S. Park, T.-H. Park, J.J. Lee, J. Joo, J. Vac. Sci. Technol. A, 18 (2), 524 (2000). DOI: 10.1116/1.582219

[3] И.И. Аксёнов, Вакуумная дуга в эрозионных источниках плазмы (ННЦ ХФТИ, Харьков, 2005).

[4] N.V. Gavrilov, A.S. Kamenetskikh, P.V. Tretnikov, A.V. Chukin, Surf. Coat. Technol., 337, 453 (2018). DOI: 10.1016/j.surfcoat.2018.01.058

[5] Н.В. Гаврилов, А.И. Меньшаков, Приборы и техника эксперимента, № 5, 140 (2011). [Пер версия: 10.1134/S0020441211050046].

[6] G.Y. Yushkov, A. Anders, E.M. Oks, I.G. Brown, J. Appl. Phys., 88 (10), 5618 (2000). DOI: 10.1063/1.1321789

[7] A.I. Hershcovitch, Appl. Phys. Lett., 68 (4), 464 (1996). DOI: $10.1063 / 1.116414$

[8] G.V. Samsonov, Nitrides (Naukova Dumka, Kiev, 1969), p. 138. 